\title{
15 才生徒における歯周疾患調査
}

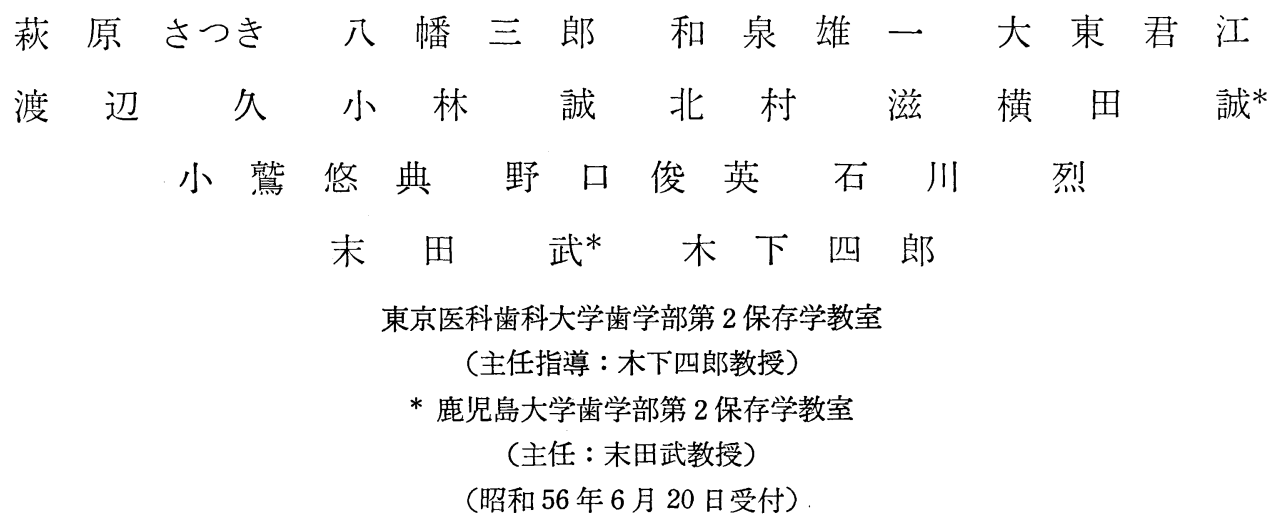

Prevalence of Periodontal Disease in 15-year-old Schoolchildren in Japan

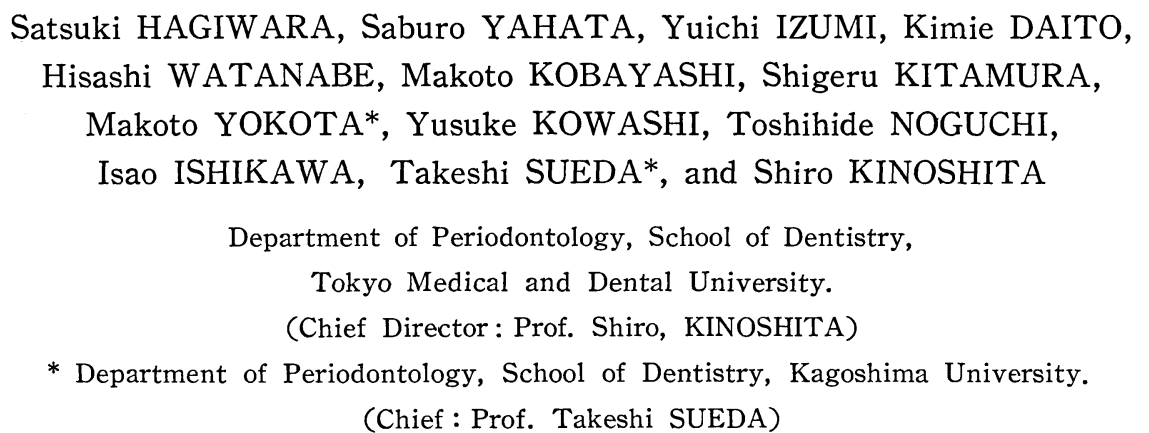

Abstracts

The purpose of this study was to determine the prevalence of periodontal disease in 690 15-year-old school children, living in Tokyo, Japan. This clinical survey was performed prior to the roentogenografic examination which was intended to study the prevalence of marginal bone loss.

Plaque Index (by Silness and Löe) and Gingival Index (by Löe and Silness) were recorded on maxillary right first molar, left incisor, first premolar, mandibular left first molar, right premolar and right incisor. Pocket depth was measured in $\mathrm{mm}$ at the six teeth, maxillary and mandibular first molars, and incisors on the mesial sides. Bleeding Index during

本論文の要旨は, 昭和 55 年 10 月, 第 23 回秋季日本歯病周 学会総会において発表した。 probing (by Ainamo) was also recorded.

The means of the Plaque Index were 1.00 and 1.30 in girl and boy students respectively. The girl students were statistically superior $(p<0.05)$ than the boys in oral prophylaxis. About 60 per cent of the children exhibited gingival inflammation as indicated more than 1.00 of Gingival Index. Very severe inflammation more than 2.00 of Gingival Index was observed about 1 per cent among the school children. About 30 per cent of the examined teeth showed pockets deeper than $2 \mathrm{~mm}$. About 10 per cent of the examined teeth were bleeded on probing.

These results suggest that periodontal breakdown was occured on more than 10 per cent the 15-year-old school children. Periodontal care and education are necessary to early teen aged children. 


\section{I. 緒言}

10 代の青少年の多くが程度のいかんにかかわらず歯 肉炎に罹患していること，そして歯周組織の破壊は 13 ないし15 歳頃から見出されることが知られている。ま た最近では臨床的に歯周疾患の特殊な型として若年性歯 周炎が注目されてきている。この疾患で㳊第 1 大目歯と 前歯部に著しい組織破壊が多く認められているが，罹患 状態はまだ正確に把握されていない。1979 年に Norway の Oslo 大学が中心となり『15 歳の生徒の歯周疾患の程 度，罹患率に関する国際的調査』が計画され，本調查に 協力の依頼を受けた。この計画は 25 力国で実施され， 各国で約 500 人の 15 歳の生徒を対象に咬翼法によるレ ントゲン写真から骨吸収の有無を調べることであった。 私達はこの依頼に対し，本邦でこのような疫学調査が少 ないこと，またその結果の国際比較ができることなどを 検討し, 1979 年 8 月東京都内の高等学校 2 校の協力を得 て 15 歳生徒の $X$ 線検診を行ない，これと同時に口腔の 状態を調べるために口腔内検診をも合わせて行なった。 その結果について，今回は口腔内検診に関して 報告す る。

\section{II. 材料と方法}

口腔検診を受診した生徒は A，B 2 つの都立高等学校 に通学する 690 人，男子 406 人，女子 284 人であった。 そのうちX線検診をも受診した生徒は 471 人, 男子 267 人，女子 204 人であった (表 1 )。

口腔検診は両校の保健室ならびに講堂で，挆針，ミラ 一ポ゚ット探針を用いて行なった。被験歯として上顎 右第 1 大臼歯, 上顎左中切歯, 上萼左第 1 小目歯, 下顎 右第 1 小臼歯, 下澦右中切歯, 下䫑左第 1 大臼歯を選択

表 1 検診を受けた生徒の人数

\begin{tabular}{|c|c|c|c|c|c|c|}
\hline & \multicolumn{3}{|c|}{$\begin{array}{l}\text { 口㛊検診を受けた } \\
\text { 生徒の数 }\end{array}$} & \multicolumn{3}{|c|}{$\begin{array}{l}\text { 口腔検診・X線検釷方を受けた } \\
\text { 生徒の数 }\end{array}$} \\
\hline & 男子 & 女子 & 総数 & 男子 & 女子 & 総数 \\
\hline A高校 & 273 & 109 & 382 & 161 & 71 & 232 \\
\hline $\mathrm{B}$ 高校 & 133 & 175 & 308 & 106 & 133 & 239 \\
\hline 計 & 406 & 284 & 690 & 267 & 204 & 471 \\
\hline
\end{tabular}

し, Silness \& Löe ${ }^{1)}$ による Plaque Index と, Löe \& Silness ${ }^{2)}$ による Gingival Index を測定し，また上下顎 左右第 1 大臼歯と上顎左中切歯，下顎右中切歯の 6 歯の 近心煩側における pocket depth, Ainamo による Gingival Bleeding Index ${ }^{3)}$ を計測した。測定にあたって， 本教室員がトレーニングを行なった。

Pocket depth は mm 単位で表わし, Gingival Bleeding Index は pocket depth を測定する際にポケット探 針で pocket の入口付近を荷重 20〜25 g 程度の力で一 度擦かした時出血した歯種を調べ，測定した歯数に対す る割合を百分率で表わした (図 1)。

\section{III. 結 果}

口腔検診の結果から歯種別, 性別, 学校別に Plaque Index, Gingival Index, pocket depth, Gingival Bleeding Index について平均值およびその分布状態や割合を 求めた。

1. Plaque Index の平均值：X線検診と口腔検診の 両方を受診した生徒は 口腔検診を受診した 総数の約 68 \%であった。X線検診をも受診した生徒の測定值との間 に違いがあるかどうかを知るために，2つのグループに 分けて平均值を求めた。口腔検診とX線検診の両方を受 診したグループの Plaque Index は性別, 学校別いずれ においても口腔検診を受診したグループの值との間に有 意差はみられなかった。また口腔検診とX線検診の両方 を受診したグループにおいて，A高校では男子の平均值

表 2 Plaque Index の平均值 (学校別)

(Mean \pm S.D.)

\begin{tabular}{|c|c|c|c|c|c|c|c|}
\hline & & $\mathrm{A}$ 高校 & & $\mathrm{N}$ & $\mathrm{B}$ 高 校 & & $\mathrm{N}$ \\
\hline \multirow{3}{*}{$\begin{array}{l}\text { 口腔検診 } \\
\text { を受けた } \\
\text { グループ }\end{array}$} & 子 & $1.26 \pm 0.62$ & $*$ & 271 & $1.27 \pm 0.53$ & & 132 \\
\hline & \begin{tabular}{|l} 
女 \\
子 \\
\end{tabular} & $1.03 \pm 0.55$ & & 99 & $1.18 \pm 0.54$ & & 176 \\
\hline & \begin{tabular}{|l} 
総 \\
数 \\
\end{tabular} & $1.20 \pm 0.61$ & & 370 & $1.22 \pm 0.54$ & & 308 \\
\hline \multirow{3}{*}{$\begin{array}{l}\text { 口腔検診 } \\
\text { とX線検 } \\
\text { 診の闭方 } \\
\text { を受けた } \\
\text { グループ }\end{array}$} & 男 & $1.30 \pm 0.62$ & $*$ & 154 & $1.29 \pm 0.53$ & & 98 \\
\hline & $\begin{array}{l}\text { 女 } \\
\text { 子 }\end{array}$ & $1.00 \pm 0.53$ & & 55 & $1.15 \pm 0.52$ & $*$ & 134 \\
\hline & $\begin{array}{l}\text { 総 } \\
\text { 数 }\end{array}$ & $1.23 \pm 0.61$ & & 209 & $1.21 \pm 0.53$ & & 232 \\
\hline
\end{tabular}

$* \mathrm{P}<0.05$ 
No. Name $\quad \operatorname{Sex}() \quad$ Age () Examiner

Plaque Index

\begin{tabular}{|c|c|c|c|c|c|c|c|c|c|c|c|}
\hline \begin{tabular}{l|l}
2 & 0
\end{tabular} & & & & & 2 & 0 & 2 & 0 & & & \multirow{4}{*}{ 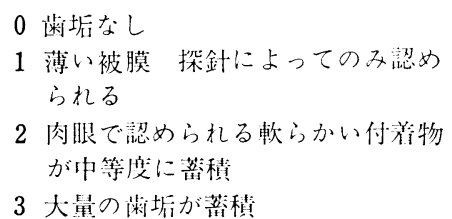 } \\
\hline 3 & & & & & 3 & 1 & 3 & 1 & & & \\
\hline \multirow[t]{3}{*}{6} & \multicolumn{2}{|c|}{4} & \multicolumn{2}{|c|}{1} & & & & & \multicolumn{2}{|c|}{6} & \\
\hline & 2 & 0 & 2 & 0 & & & & & 2 & 0 & \\
\hline & 3 & 1 & 3 & 1 & & & & & 3 & 1 & \\
\hline
\end{tabular}

Gingival Index
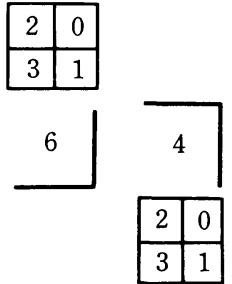
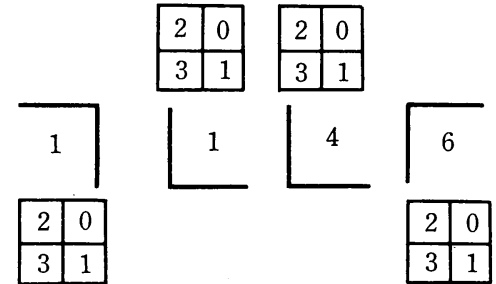

Pocket Depth (mesial)

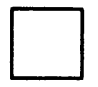

6

1

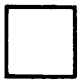

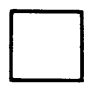

1

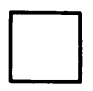

6
0 正波战肉

1 軽い炎症: 色淍でわずかな変化 わ ずかの腄肶

2 中程度の炎症 発赤崏服 プロー ビングで姑血

3 高度の炎症: 著明な発赤溃㳑 寸 ぐに肿佔

$\mathrm{mm}$ 単位であらわす

最大值

Missing Tooth

Gingival Bleeding

Pocket 測定の際 蛙したた時は 】をつで囲んで下さい

Pocket 测定にあたっては，非常におだやかな力で测定すること 加圧（20～25g）をこえないこと

図 1 口腔検診記録用紙

が 1.30 , 女子の平均值が $1.00, \mathrm{~B}$ 高校では男子の平均值 が 1.29, 女子の平均值が 1.15 で男女の Plaque Index の平均值の間に有意水準 $5 \%$ で差が認められた。即ち 男子の方が口腔清掃状態が劣っていた（表 2 ，表 3)。

2. Plaque Index の分布状態: Plaque Index が 1 以 下の生徒は両校合わせた場合, 男子 $27.8 \%$, 女子 32.8 $\%$ で全体の約 $1 / 3$ であった。 1 以上 2 以下の生徒は男 子，女子とも $59.1 \%$ で全体の約 6 割を占めており， 2 以上 3 以下の生徒は男子 $13.0 \%$, 女子 $8.0 \%$ で全体の 約 1 割を占めていた (図 2)。
3. 歯種別の Plaque Index の分布状態 : Plaque Index は表 4 に示したような順で上顎第 1 大臼歯が最大值 を示し，下顎第 1 小臼歯が最小值を示した。

4. Gingival Index の平均值: 口腔検診と X線検診 の両方を受診したグループの Gingival Index は性別, 学校別のいずれにおいても口腔検診を受診したグループ との間に有意差は認められなかった。また 2 校とも男女 の值の間に有意差はなかった。口腔検診とX線検診の両 方を受診したグループにおいて，A 高校，B 高校を合わ せた男子の平均值は 0.93 ，女子では 0.88 であり，男女 
表 3 Plaque Index の平均值

(Mean \pm S.D.)

\begin{tabular}{|c|c|c|c|c|}
\hline & & \multicolumn{2}{|c|}{ A高校+B高校 } & 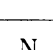 \\
\hline \multirow{3}{*}{$\begin{array}{l}\text { 口舵検診を } \\
\text { 受けだだ } \\
\text { ープ }\end{array}$} & 男子 & $1.26 \pm 0.60$ & * & 403 \\
\hline & 好了。 & $1.13 \pm 0.55$ & & 275 \\
\hline & 総数 & $1.21 \pm 0.58$ & & 678 \\
\hline \multirow{3}{*}{$\begin{array}{l}\text { 口脱検診と } \\
\text { X線娭診の } \\
\text { 崩方を受け } \\
\text { たグループ }\end{array}$} & 男子 & $1.30 \pm 0.59$ & $*$ & 252 \\
\hline & 女子 & $1.11 \pm 0.53$ & & 189 \\
\hline & 総数 & $1.22 \pm 0.57$ & & 441 \\
\hline
\end{tabular}

$* \mathrm{P}<0.05$

表 4 歯種別の Plaque Index の平均値（口腔 検診を受けたグループについて)

$\mathrm{A}$ 高校 $+\mathrm{B}$ 高校 (Mean \pm S.D.)

\begin{tabular}{c|c|c|c}
\hline & 男子 & 女子 & 総 数 \\
\hline 6 & $1.37 \pm 0.80$ & $1.27 \pm 0.75$ & $1.34 \pm 0.78$ \\
\hline 4 & $1.14 \pm 0.75$ & $0.97 \pm 0.66$ & $1.07 \pm 0.72$ \\
\hline 1 & $1.33 \pm 0.81$ & $1.25 \pm 0.73$ & $1.30 \pm 0.78$ \\
\hline\lfloor & $1.27 \pm 0.83$ & $1.01 \pm 0.71$ & $1.17 \pm 0.80$ \\
\hline$\lfloor 4$ & $1.20 \pm 0.79$ & $0.96 \pm 0.73$ & $1.10 \pm 0.77$ \\
\hline$\sqrt{6}$ & $1.33 \pm 0.69$ & $1.16 \pm 0.70$ & $1.27 \pm 0.70$ \\
\hline
\end{tabular}

Plaque Indexの平圴値の大きさの順

$$
\text { (総数) } 6\rfloor>\sqrt{1}>\sqrt{6}>\lfloor 1>\lfloor 4>4
$$

間, 学校間で平均値はほぼ一定の值を示した（表 5 , 表 6 )。

5. Gingival Index の分布状態: Gingival Index が 1 以下の生徒の占める割合は, 両校合わせた場合は男子 $42.5 \%$ ，女子 $42.0 \%$ であった。Gingival Index が 1 以 上の歯肉には, 明らかに発赤腫脹が見られることから， 臨床上病的状態といえる。そこで Ginngival Index が 1 以上の值を有する生徒の分布状態をみると約 $60 \%$ の 生徒が既に歯肉炎に罹患していることがわかった。その うち特に值が 2 以上の者は, 学校別, 男女別で差はあっ たが，1〜2\%に見られた (図 3 )。

6. 歯種別の Gingival Index の分布状龍 : 表 7 に示 すような順で，最大值を示したのは下䫟中切歯で，最小
表 5 Gingival Index の平均值 (学校別)

(Mean \pm S.D.)

\begin{tabular}{|c|c|c|c|c|c|}
\hline & & $\mathrm{A}$ 高校 & $\mathrm{N}$ & B 高校 & $\mathrm{N}$ \\
\hline \multirow{3}{*}{$\begin{array}{l}\text { 口腔検診 } \\
\text { 受けた } \\
\text { グループ }\end{array}$} & $\begin{array}{l}\text { 男 } \\
\text { 子 }\end{array}$ & $0.86 \pm 0.51$ & 190 & $0.96 \pm 0.45$ & 130 \\
\hline & $\begin{array}{l}女 \\
子 \\
\end{array}$ & $0.80 \pm 0.44$ & 62 & $0.91 \pm 0.39$ & 175 \\
\hline & $\begin{array}{l}\text { 総 } \\
\text { 数 }\end{array}$ & $0.84 \pm 0.50$ & 252 & $0.93 \pm 0.41$ & 305 \\
\hline \multirow{3}{*}{$\begin{array}{l}\text { 口脘検診 } \\
\text { とX線検 } \\
\text { 診の邨 } \\
\text { を受けた } \\
\text { グループ }\end{array}$} & $\begin{array}{l}\text { 男 } \\
-\end{array}$ & $0.87 \pm 0.56$ & 94 & $0.99 \pm 0.44$ & 98 \\
\hline & $\begin{array}{l}x \\
\end{array}$ & $0.81 \pm 0.42$ & 35 & $0.89 \pm 0.40$ & 134 \\
\hline & 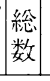 & $0.85 \pm 0.53$ & 129 & $0.93 \pm 0.42$ & 232 \\
\hline
\end{tabular}

表 6 Gingival Index $の$ 平均值

(Mean \pm S.D.)

\begin{tabular}{|c|c|c|c|}
\hline & \multicolumn{2}{|c|}{$\mathrm{A}$ 高校+ $\mathrm{B}$ 高校 } & $\mathrm{N}$ \\
\hline \multirow{3}{*}{$\begin{array}{l}\text { 口腔検診を } \\
\text { 受けだ゙ル } \\
\text { ープ }\end{array}$} & 男子 & $0.90 \pm 0.49$ & 320 \\
\hline & 女子 & $0.88 \pm 0.41$ & 237 \\
\hline & 総 数 & $0.89 \pm 0.46$ & 557 \\
\hline \multirow{3}{*}{$\begin{array}{l}\text { 口腔検診と } \\
\text { X線検診の } \\
\text { 両方を受け } \\
\text { たグループ }\end{array}$} & 男子 & $0.93 \pm 0.51$ & 192 \\
\hline & 女子 & $0.88 \pm 0.41$ & 169 \\
\hline & 総数 & $0.90 \pm 0.46$ & 361 \\
\hline
\end{tabular}

Plaque Index (百分摔)

(P.I.)

(口腔唡診を受けたグループについて)
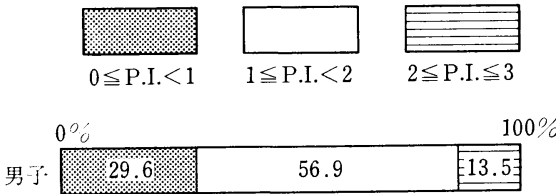

A 高校

\begin{tabular}{|c|c|c|}
\hline & & 48.5 \\
\hline
\end{tabular}

B 高校

男子 24.2 . $24.6 \quad 12.1$

\begin{tabular}{|c|c|c|c|c|}
\hline 8 & 女子 & $26.9 \%$ & 65.1 & 8.0 \\
\hline 高校 & 男子 & 27.8 & 59.1 & 13.0 \\
\hline${ }^{+}{ }^{+}$高校 & 女 & 32.8 & 59.1 & 8 \\
\hline
\end{tabular}

図 2 
Gingival Index (直分洋)

(G.I.)

（口腔椮觖を受けたグループについて）
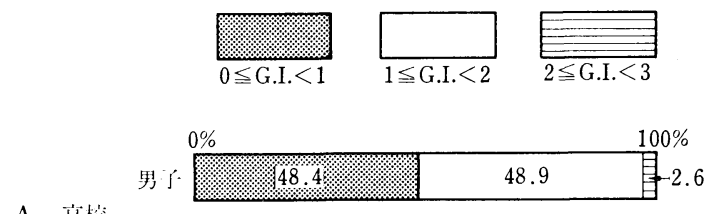

A 苚校
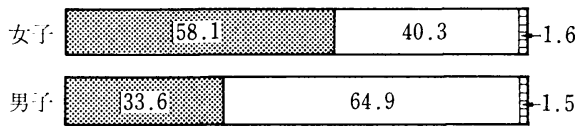

B 简校

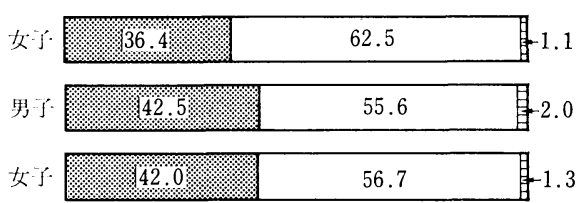

図 3

Pocket Depth の百分㳯表示

(P.D.)

$(\mathrm{A}$ 高校+ B吕校 総数 $)$
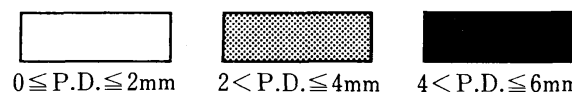

$0 \%$

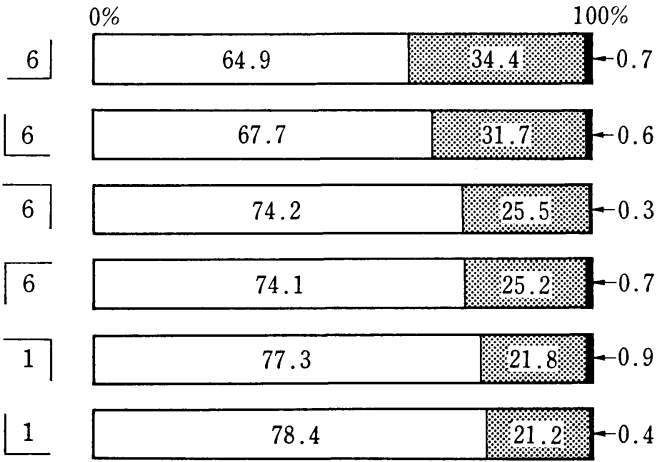

図 4

值を示したのは下䫟第 1 小臼歯であった。

7. 歯種別の pocket depth の平均值 : 上顎第 1 大臼 歯近心煩側の pocket depth は $2.39 \mathrm{~mm}$ で, 他の歯種 に比較して最も值が大きかった。その他の歯種の pocket depth の平均值は表 8 に示した。

8. 歯種別の pocket depth $の$ 分布 状態 : pocket depth の測定值の範囲は $1 \mathrm{~mm}$ から $6 \mathrm{~mm}$ であった。 なお各歯種で $5 \mathrm{~mm}$ 以上の pocket を有する生徒が占め る割合は $0.3 〜 0.9 \%$ であった。 $3 \mathrm{~mm}$ 以上の pocketを
表 7 歯種別の Gingival Index の平均值（口腔検 診を受けたグループについて)

$\mathrm{A}$ 高校 $+\mathrm{B}$ 高校 (Mean \pm S.D.)

\begin{tabular}{c|c|c|c}
\hline & 男子 & 女子 & 総 数 \\
\hline 6 & $0.94 \pm 0.61$ & $0.90 \pm 0.56$ & $0.92 \pm 0.59$ \\
\hline 4 & $0.86 \pm 0.63$ & $0.79 \pm 0.53$ & $0.83 \pm 0.59$ \\
\hline 1 & $1.08 \pm 0.66$ & $1.04 \pm 0.63$ & $1.06 \pm 0.65$ \\
\hline 4 & $0.97 \pm 0.64$ & $0.90 \pm 0.61$ & $0.94 \pm 0.63$ \\
\hline 4 & $0.93 \pm 0.61$ & $0.83 \pm 0.57$ & $0.89 \pm 0.59$ \\
\hline \hline 6 & $0.90 \pm 0.56$ & $0.89 \pm 0.54$ & $0.89 \pm 0.55$ \\
\hline
\end{tabular}

Gingival Indexの平坻值の大きさの順

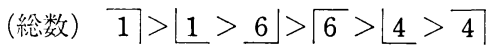

表 8 Pocket Depth の平均值（口腔検診を 受けたグループについて)

(Mean \pm S.D.)

\begin{tabular}{|c|c|c|c|}
\hline & \multicolumn{2}{|c|}{$\mathrm{A}$ 高校と $\mathrm{B}$ 高校 } & $(\mathrm{mm})$ \\
\hline & 男子 & 女子 & 総 数 \\
\hline 6 & $2.39 \pm 0.74$ & $2.35 \pm 0.74$ & $2.37 \pm 0.74$ \\
\hline 6 & $2.24 \pm 0.76$ & $2.15 \pm 0.66$ & $2.20 \pm 0.73$ \\
\hline 1 & $2.16 \pm 0.88$ & $2.11 \pm 0.79$ & $2.14 \pm 0.84$ \\
\hline 1 & $2.14 \pm 0.86$ & $2.30 \pm 0.82$ & $2.09 \pm 0.82$ \\
\hline 6 & $2.38 \pm 0.75$ & $2.30 \pm 0.82$ & $2.35 \pm 0.78$ \\
\hline$\longdiv { 6 }$ & $2.28 \pm 0.78$ & $2.16 \pm 0.69$ & $2.23 \pm 0.75$ \\
\hline
\end{tabular}

Pocket Depthの平均值の大きさの順

(総数) $6|>| 6>\sqrt{6}>6\rceil>1\rceil>\lfloor 1$

有する生徒が占める割合では上頡第 1 大臼 歯が 32〜35 $\%$ と大きく, 上顎中切歯では $21 \%$ と小さかった (図 4)。

9. 歯種別の Gingival Bleeding Index : 下顎中切歯 は $12.1 \%$ と最大值を示した。平均して約 $10 \%$ に出血 が認められた（表 9)。

10. Plaque Index, Gingival Index, Pocket depth 間の相関性：3 種の測定值の間に相関があるかどうかに ついて調べた。後に Bone Loss と口腔検診の結果との 相関について調べるのに都合が良い様に, Plaque Index, Gingival Index, Pocket depth, Bone Loss の 4 点につ いて比較しうる歯種である上頡右第 1 大兒歯と下顎左第 1 大臼歯を代表歯として選択した。2つの歯種につい て，2校とも Plaque Index と Gingival Index の間に 
GINGIVAL BLEEDING INDEX

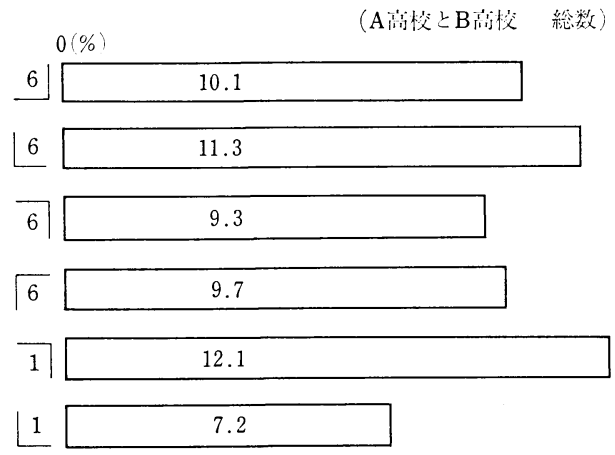

図 5

有意水準 $1 \%$ で相関が認められた。上顎右第 1 大臼歯 では B 高校において Plaque Index と Pocket depth の 間, Gingival Index と Pocket depth の間にも有意水淮 $5 \%$ で相関が認められた（表 $10 ，$ 表 11 )。

\section{IV. 考察}

この 15 歳の生徒 690 人を対象にした口腔検診の結果 約 $60 \%$ に歯肉炎が見られた。そのうち約 $1 \%$ に歯肉の 炎症症状が強く認められた。また， $2 \mathrm{~mm}$ 以上のポケッ 卜形成が約 20〜30\% に見られた。ポケット測定の際に 出血が約 10\% にみられた。これらを考慮すると, 15 歳 の時点ですでに歯周炎へと進行している生徒がみられる ことが推察された。後に骨吸収の程度を調べたところ, $2 \mathrm{~mm}$ 以上の骨吸収 (cement-enamel junction と骨頂部 との距離を測定）が認められた生徒の占める 割 合が約 $8.5 \%$ であったことからこの推測はある程度裏付けされ た)。

Attström 等5) は 14〜16 歳生徒の口腔内検診を行ない, $74 \%$ の生徒が少なくとも 1 歯に樑い歯周ポケットを持 ち, ポケット測定の際に多くのポケットから出血したこ とから，ポケット底部が cement-enamel junction から 根尖側へ移動している危険性があると考えた。

Sheiham 等6) はイギリスの 15〜17 歳の生徒は約 $25 \%$ に，1つあるいはそれ以上の歯周ポケットを持つが， Sinclair と Goose ${ }^{7)}$ はイギリスの Cheshire において 12〜17 歳の生徒には真の歯周ポケットはみられなかっ たと報告している。

Anaise ${ }^{8)}$ は Russel の P.I. を用いて検診を行なったが Israel の 14 17 歳の生徒には進行性の歯周疾患は認め られなかったと報告している。このことは検診を行なう
表 9 Bleeding Index（口腔検診を受けた グループについて)

\begin{tabular}{c|c|c|c}
\hline \multicolumn{4}{c}{$\mathrm{A}$ 高校と B 高校 } \\
\hline & 男子 & 女子 & 総 数 \\
\hline 6 & 8.8 & 11.8 & 10.1 \\
\hline 6 & 9.8 & 8.6 & 9.3 \\
\hline 1 & 11.4 & 13.2 & 12.1 \\
\hline 1 & 7.9 & 6.0 & 7.2 \\
\hline 6 & 10.7 & 12.2 & 11.3 \\
\hline 6 & 8.4 & 11.7 & 9.7 \\
\hline
\end{tabular}

表 $1 0 \longdiv { 6 }$ の Plaque Index (P.I.), Gingival Index (G.I.) と Pocket Depth (P.D.) (口腔検診とX線検診の両方を受けたグ ループについて)

\begin{tabular}{l|ccc|ccc}
\hline & \multicolumn{3}{|c|}{ A 高校 } & \multicolumn{3}{c}{ B 高校 } \\
\hline & Mean & S.D. & $\mathrm{N}$ & Mean & S.D. & $\mathrm{N}$ \\
\hline Plaque Index & 1.21 & 0.67 & 135 & 1.26 & 0.68 & 185 \\
Gingival Index & 0.72 & 0.62 & 135 & 0.91 & 0.54 & 185 \\
Pocket Depth & 2.34 & 0.83 & 135 & 2.02 & 0.63 & 185 \\
\hline & \multicolumn{3}{|c|}{$\mathrm{r}$} & \multicolumn{3}{|c}{$\mathrm{r}$} \\
\hline P.I. $\rightarrow$ G.I . & $0.2716^{* *}$ & \multicolumn{3}{|c}{$0.3974^{* *}$} \\
P.I. $\rightarrow$ P.D. & 0.0500 & \multicolumn{3}{|c}{0.0928} \\
G.I. $\rightarrow$ P.D. & -0.0101 & \multicolumn{3}{|c}{0.0699} \\
\hline
\end{tabular}

${ }^{* *} \mathrm{P}<0.01$

表 11 6 Index (G.I.) Pocket Depth (P.D.) （口腔検診とX線検診の両方を受けたグ ループについて)

\begin{tabular}{|c|c|c|c|c|c|c|}
\hline & \multicolumn{3}{|c|}{$\mathrm{A}$ 高校 } & \multicolumn{3}{|c|}{$\mathrm{B}$ 高校 } \\
\hline & Mean & S.D. & $\mathrm{N}$ & Mean & S.D. & $\mathrm{N}$ \\
\hline Plaque Index & 1.33 & 0.87 & 131 & 1.26 & 0.75 & 183 \\
\hline Gingival Index & 0.76 & 0.68 & 131 & 0.87 & 0.52 & 183 \\
\hline \multirow[t]{2}{*}{ Pocket Depth } & 2.41 & 0.77 & 131 & 2.22 & 0.76 & 183 \\
\hline & \multicolumn{3}{|c|}{$\mathrm{r}$} & \multicolumn{3}{|c|}{$\mathbf{r}$} \\
\hline P.I. $\rightarrow$ G.I . & \multicolumn{3}{|c|}{$0.4059^{* *}$} & \multicolumn{3}{|c|}{$0.4443^{* *}$} \\
\hline P.I. $\rightarrow$ P.D. & \multicolumn{3}{|c|}{0.1126} & \multicolumn{3}{|c|}{$0.1782^{*}$} \\
\hline G.I. $\rightarrow$ P.D. & \multicolumn{3}{|c|}{0.1598} & \multicolumn{3}{|c|}{$0.1798^{*}$} \\
\hline
\end{tabular}


時の診断基準の違いに加えて, 地域における生活様式の 相違も影響していると考えられる。

このように 15 歳生徒の口腔検診において様々な結果 が得られている。

今回私達はポケット測定を煩側近心部について行なっ た。上下顎第 1 大臼歯のポケットは上下顎中切歯より深 いことから，大臼歯の歯間部の清掃状態は不良であり， 炎症症状も呈していると考えられた。これは pocket depth においては上下䫠第 1 大臼歯が最も梁く，またこ の歯種の Plaque Index が最大であったことからも明ら かである。

Gingival Bleeding Index に扔いて下顎中切歯が最大 値を示したことは, この歯種の Gingival Index が最も 高かったことと関係があると思われる。即ち，歯垢に加 えてその他の生理的な要因, 例えば歯石の沈着や口呼吸 などが影響していると思われる。

約 $60 \%$ の生徒に歯肉炎が認められたことから，この 年代の生徒に対して治療の必要があると考えられる。

また今回の検診の 1 つの目的である 15 歳生徒に若年 性歯周疾患が見られるかどうかについては口腔内所見の みからは証明でなかった。咬翼法によるX線写真の読影 を行なったところ数名に骨吸収の大きい像が見られた た が，その原因について様々な因子が考えられたため，こ れらが若年性歯周炎の徴候であると判断するには，より 詳細な診查が必要であると思われた。

\section{V. 結 論}

15 歳の生徒 690 人において約 $60 \%$ に明らかな歯肉炎 が認められた。そのうちの約 1\% は高度の炎症症状を 呈していた。 $2 \mathrm{~mm}$ 以上の歯周ポケットは全ての被験歯 の約 $20 \sim 30 \%$ に見られた。歯種別にみると上顎第 1 大 臼歯の pocket depth は平均值 $2.36 \mathrm{~mm}$, plaque Index は平均值 1.34 で，ともに最大値を示した。
謝 辞

この研究において, 検診, 資料収集に御協力頂きました東京 医科歯科大学歯学部第 2 保存学教室, 歯科放射線学教室の皆様 に厚く御礼申し上げます。

また検診に御協力下さいました都立両国高校, 都立駒場高校 両校の皆様に深く感謝の意を表します。

\section{文献}

1) Silness, J., and Löe, H. : Periodontal disease in pregnancy. II. Correlation between oral hygiene and periodontal condition. Acta Odont. Scand. $22: 121,1964$.

2) Löe, H., and Silness, J. : Periodontal disease in pregnancy. I. Prevalence and severity. Acta Odont. Scand. $21: 533,1963$.

3) Ainamo, J., and I. Bay. : Problems and proposals for recording gingivitis and plaque. Int. Dent. J. 25 : 229-235, 1975.

4）八幡三郎，萩原さつき，松尾良平，村岡宜明，小 田茂, 東克章, 長田豊, 和泉雄一, 米良豊常, 田 中敬子, 石川烈, 木下四郎：第 74 回春季日本歯 科保存学会発表, 新潟, 1981.

5) Jeyaraj, N.H., Birgit, E., and R. Attström : Periodontal status of 14-16-year-old Danish school-children. Scand. J. Dent. Res. 89 : 175179, 1981.

6) Sheiham, A. : The prevalence and severity of periodontal disease in British populations. Br. Dent. J. 126 : 115-121, 1969.

7) Sinclair, V., and Goose, D.H. : The periodontal condition of grammer school children in Cheshire. Br. Dent. J. 1966 : 121 : 420-423, 1966.

8) Tirosh, A., and Anaise, J.Z. : Prevalence of caries and periodontal disease and oral hygiene status in urban teenagers (15-17 years of age). Isr. J. Med. $28: 39-43,1979$. 